\title{
EFEITO DE DIFERENTES DOSES DE COMPOSTOS ORGÂNICOS E FERTILIZANTES NPK NO DESENVOLVIMENTO E PRODUTIVIDADE DE CEBOLA
}

\author{
Elaine Oliveira Costa de Carvalho, Antônio Anicete de Lima, Ary Eike Siqueira Silva Junior, \\ Luciane da Cunha Codognoto, Anthonioni Peron Dal Sasso, \\ DARLlAN JUNiOR LUiz SANTOS FERREIRA DE OLIVEIRA
}

Instituto Federal de Educação, Ciência e Tecnologia de Rondônia (IFRO), Campus Ariquemes <elaine.carvalho@ifro.edu.br>.<antonio.anicete@ifro.edu.br>,<ary-eike@bol.com.br>. <luciane.codognoto@ifro.edu.br>.<anthonioni.sasso@ifro.edu.br>.<darllan_junior58@hotmail.com>

DOI: $10.21439 /$ conexoes.v11i4.1044

\begin{abstract}
Resumo. Este trabalho foi conduzido em condições de campo, com o objetivo de avaliar o desenvolvimento e a produtividade da cebola cv. Crioula submetida a diferentes doses de composto orgânico e níveis de adubação NPK. As mudas foram transplantadas em canteiros, com delineamento experimental em blocos casualizados, fatorial $4 \times 2$, sendo o primeiro tratamento constituído de doses de composto orgânico $\left(0,3,6\right.$ e $\left.9 \mathrm{~L} \mathrm{~m}^{-2}\right)$ e o segundo, de níveis de fertilizantes minerais $(\mathrm{N}-5$ e N-9, correspondentes a $50 \%$ e $90 \%$, respectivamente, da recomendação da adubação de $\mathrm{N}, \mathrm{P}_{2} \mathrm{O}_{5}$ e $\mathrm{K}_{2} \mathrm{O}$ ), com quatro repetições. A colheita ocorreu 131 dias após a semeadura e a produtividade máxima de bulbos comercializáveis foi de $4,77 \mathrm{~kg} \mathrm{~m}^{-2}$. O número de plantas que não bulbificaram diminuiu com o aumento das doses de composto em até $43,5 \%$, quando foi aplicado o tratamento N-9 e de $15,4 \%$ para N-5, da dose de NPK recomendada para a cebola. Doses crescentes de compostos orgânicos aumentaram a produção de bulbos podres, correspondendo a 21,43\% para N-5 na dose de $9,0 \mathrm{~L} \mathrm{~m}^{-2}$ e em 18,12\% para N-9 na dose estimada de $4,7 \mathrm{~L} \mathrm{~m}^{-2}$. Não houve efeito dos tratamentos na produção de bulbos com diâmetro inferior a $35 \mathrm{~mm}$, média de $0,59 \mathrm{~kg} \mathrm{~m}^{-2}$, no estande final e no número de plantas com doenças foliares. A cv. Crioula pode ser recomendada para plantio, nas condições desse experimento de clima tropical úmido e solos de baixa fertilidade, desde que sejam feitas as devidas correções e adubações preconizadas para a cultura.
\end{abstract}

Palavras-chaves: Allium cepa L. Adubos orgânicos. Fertilizantes minerais.

\begin{abstract}
This work was carried out under field conditions, with the aim of evaluate the growth and yield of onion cv. Crioula exposed to different concentrations of organic compound and NPK fertilizer levels. The seedlings were transplanted on seedbeds beds, with a randomized block design factorial $4 \times 2$, with the first treatment consists of doses of organic compost $\left(0,3,6\right.$ and $\left.9 \mathrm{~L} \mathrm{~m}^{-2}\right)$ and the second mineral fertilizer levels ( $\mathrm{N}-5$ and $\mathrm{N}-9$, corresponding to $50 \%$ and $90 \%$, respectively, of the recommendation of fertilizers $\mathrm{N}, \mathrm{P}_{2} \mathrm{O}_{5}$ and $\mathrm{K}_{2} \mathrm{O}$ ), with four replications. The harvest took place 131 days after sowing and the maximum yield of marketable bulbs was $4.77 \mathrm{~kg} \mathrm{~m}^{-2}$. The number of plants that do not bulbing decreased with increasing doses of the compound up to $43.5 \%$ when the treatment $\mathrm{N}-9$ was applied and $15.4 \%$ for N-5, of NPK dose recommended for onion. Increasing doses of organic compounds increased the production of rotten bulbs, corresponding to $21.43 \%$ for $\mathrm{N}-5$ at a dose of $9.0 \mathrm{~L} \mathrm{~m}^{-2}$ and $18.12 \%$ for $\mathrm{N}-9$ an estimated dose of $4.7 \mathrm{~L} \mathrm{~m}^{-2}$. There was no effect of the treatments in the production of bulbs with a diameter less than $35 \mathrm{~mm}$, average of $0.59 \mathrm{~kg} \mathrm{~m}^{-2}$, in the final stand and the number of plants with leaf diseases. The cv. Crioula can be recommended for planting in the conditions of humid tropical climate this experiment and low fertility soils, provided they are made the recommended corrections and fertilizers for culture.
\end{abstract}

Keywords: Allium cepa L. Organic manures. Mineral fertilizers. Yield. 


\section{INTRODUÇÃO}

A cebola ocupa a quarta posição no ranking nacional de produção de hortaliças, apresentado um volume anual de produção de 1.646 mil toneladas, sendo superada apenas pelas culturas do tomate, batata e melancia. As regiões sul e sudeste respondem por $62,65 \%$ da produção brasileira; a região nordeste, por $28,35 \%$ e as regiões centro-oeste e norte, por apenas $6,40 \%$ (IBGE 2014).

Aproximadamente cem por cento de toda a cebola consumida em Rondônia é proveniente das regiões sul e sudeste do Brasil, embora pesquisas indiquem a possibilidade de cultivo dessa hortaliça na região sul do estado onde as condições climáticas são mais favoráveis. Em pesquisa realizada por (LIMA et al., 2011) no município de Colorado do Oeste, utilizando diferentes genótipos de cebola, as maiores produtividades de bulbos comerciais foram obtidas com os cultivares, Aurora (45,94 $\left.\mathrm{t} \mathrm{ha}^{-1}\right)$, Pira Ouro $\left(37,84 \mathrm{t} \mathrm{ha}^{-1}\right)$ e Primavera $\left(37,03 \mathrm{t} \mathrm{ha}^{-1}\right)$, quando a semeadura foi realizada entre a segunda quinzena de abril e a primeira de maio. Ainda segundos os mesmos autores, plantios mais tardios apresentaram redução significativamente da produtividade, devido a colheita coincidir com o início do período chuvoso.

Os solos predominantes da região de Ariquemes são os Latossolos Vermelhos Amarelos e Latossolos Vermelhos distróficos, bastante intemperizados, relevo plano a suave ondulado, fertilidade natural baixa a muito baixa, necessitando de correção e adubação (MENEZES; LOCATELLI, 2008).

Nas condições de solos da região, geralmente com baixos teores de fósforo, potássio e cálcio, é necessária a aplicação de doses máximas de nutrientes por meio da utilização de calcários, fertilizantes minerais e compostos orgânicos, tendo como objetivo manter a produtividade e a qualidade da produção. Tendo em vista atender às exigências nutricionais da cebola nas condições das classes de solos mencionadas, é recomendada a aplicação de 40 a $60 \mathrm{~kg} \mathrm{ha}^{-1}$ de $\mathrm{N}$, de 300 a $400 \mathrm{~kg} \mathrm{ha}^{-1}$ de $\mathrm{P}_{2} \mathrm{O}_{5}$ e de 80 a $120 \mathrm{~kg} \mathrm{ha}^{-1}$ de $\mathrm{K}_{2} \mathrm{O}$, somente na adubação básica. As coberturas nitrogenadas recomendadas variam de 40 a $60 \mathrm{~kg} \mathrm{ha}^{-1}, 30$ a 40 dias após o transplantio (ANGELETTI; FONSECA, 1987; FILGUEIRA, 2008; RIBEIRO, 1999).

Segundo Dias e Fernandes (2006), o Brasil importa cerca de $60 \%$ dos fertilizantes nitrogenados, $45 \%$ dos fosfatados e $90 \%$ dos potássicos que são utilizados na agricultura. Reduzir a utilização de fertilizantes minerais, sem perda de produtividade e qualidade, é um grande desafio para a pesquisa. Portanto, é necessária a utilização de adubos orgânicos que, segundo as pesquisas, melhoram as condições físicas do solo, favorecem o crescimento microbiano, aumentam a disponibilidade de nutrientes, a produtividade e a CTC do solo, bem como a capacidade de infiltração de água, diminuindo, consequentemente, as perdas por erosão (PAES et al. 1996, SILVA; RESCK, 1997).

Este trabalho foi realizado com o objetivo de avaliar o crescimento e a produtividade da cebola, cultivar Crioula, cultivada em campo e submetida a diferentes doses de compostos orgânicos e níveis de fertilizantes NPK, a fim de determinar as doses de cada tratamento nas quais se obtenha a produção máxima, com redução de utilização de fertilizantes minerais.

\section{MATERIAIS E MÉTODOS}

O experimento foi conduzido no Setor de Olericultura do Instituto Federal de Rondônia, Campus Ariquemes, no período de junho a setembro de 2011. As coordenadas locais são $94^{\circ} 57^{\prime} 8^{\prime \prime}$ de latitude Sul e $62^{\circ} 57^{\prime} 45^{\prime \prime}$ de longitude Oeste, à altitude de $140 \mathrm{~m}$.

O solo do campo experimental é do tipo Latossolo Vermelho Amarelo distrófico (LVAd) e o clima, segundo a classificação de Köppen, tropical chuvoso, tipo Aw, com total pluviométrico anual oscilando entre 1.400 a $2.600 \mathrm{~mm}$, com nítido período de estiagem de 3 a 4 meses e temperatura média anual do ar variando entre 24 a $26{ }^{\circ} \mathrm{C}$ (SEDAM, 2012).

As sementes da cultivar de cebola Crioula, foram semeadas em bandejas de isopor com 200 células e irrigadas, diariamente, por meio de microaspersão, de $08 \mathrm{~h} 00 \mathrm{~min}$ às $17 \mathrm{~h} 00 \mathrm{~min}$, com tempo de funcionamento de 4 minutos a cada 3 horas, pressão de funcionamento de 10 mca e vazão média de $26,0 \mathrm{~L}_{\text {hora }}{ }^{-1}$. As mudas foram transplantadas, 39 dias após a semeadura, em sulcos abertos em canteiros com 1,0 m de largura, no espaçamento de 0,25 entre linhas transversais e $0,14 \mathrm{~m}$ entre plantas.

O delineamento experimental utilizado foi de blocos casualizados, em esquema fatorial $4 \times 2$, sendo o primeiro tratamento constituído pelas doses de composto orgânico $\left(0,3,6\right.$ e $\left.9 \mathrm{~L} \mathrm{~m}^{-2}\right)$ e o segundo, pelos níveis de fertilizantes minerais $(50 \%$ e $90 \%$ da recomendação de adubação básica e em cobertura de $\mathrm{N}, \mathrm{P}_{2} \mathrm{O}_{5}$ e $\mathrm{K}_{2} \mathrm{O}$ ), com um total de 4 repetições. A unidade experimental constituiu-se de um canteiro com área de $1,5 \mathrm{~m}^{2}$, com 7,0 linhas transversais espaçadas de $0,25 \mathrm{~m} \mathrm{x} \mathrm{0,14} \mathrm{m,}$ num total de 42 plantas por parcela. Foram utilizadas, como área útil, cinco linhas centrais e quatro plantas por linha transversal, ou seja, 16 plantas por amostra. 


\section{EFEITO DE DIFERENTES DOSES DE COMPOSTOS ORGÂNICOS E FERTILIZANTES NPK NO DESENVOLVIMENTO E}

PRODUTIVIDADE DE CEBOLA

O composto orgânico foi preparado com diferentes resíduos de origem vegetal, capins, folhas secas e casca de café, sobre os quais foram adicionados $0,5 \%$ de calcário dolomítico com base no volume total dos resíduos utilizados. Esse tipo de compostagem é feito alternando-se uma camada de $20 \mathrm{~cm}$ de resíduos de origem vegetal com estercos bovino na proporção 3:1, sendo o material enleirado em pilhas de $1,2 \mathrm{~m}$ de altura por 2,0 m largura e 3,0 m de comprimento, tendo em vista favorecer a sua decomposição (OLIVEIRA; AQUINO; NETO, 2005). O composto foi utilizado 120 dias após o início da fermentação, depois de peneirado, sendo aplicado nos sulcos de plantio de forma localizada, oito dias antes do transplantio das mudas, juntamente com os fertilizantes minerais.

O composto orgânico apresentou as seguintes características químicas médias: $\mathrm{pH}$ (água) $=5,8 ; \mathrm{N}=20,4$ $\mathrm{g} \mathrm{kg}^{-1} ; \mathrm{P}=5,4 \mathrm{~g} \mathrm{~kg}^{-1} ; \mathrm{K}=14,3 \mathrm{~g} \mathrm{~kg}^{-1} ; \mathrm{Ca}=15,5 \mathrm{~g}$ $\mathrm{kg}^{-1} ; \mathrm{Mg}=4,2 \mathrm{~g} \mathrm{~kg}^{-1} \mathrm{e} \mathrm{S}=1,6 \mathrm{~g} \mathrm{~kg}^{-1} ; \mathrm{Zn}=68,0 \mathrm{mg}$ $\mathrm{kg}^{-1} ; \mathrm{Cu}=57,0 \mathrm{mg} \mathrm{kg}^{-1} ; \mathrm{B}=32 \mathrm{mg} \mathrm{kg}^{-1} ; \mathrm{Fe}=587$ $\mathrm{mg} \mathrm{kg}^{-1} \mathrm{e} \mathrm{Mn}=120 \mathrm{mg} \mathrm{kg}^{-1} ; \mathrm{C}_{\text {(org. }}=250,3 \mathrm{~g} \mathrm{~kg}^{-1}$ e $\mathrm{C} / \mathrm{N}=12,27$.

O solo utilizado para cultivo da cebola foi um Latossolo Vermelho Amarelo, textura argilosa, que apresentou, na camada de 0 a $20 \mathrm{~cm}$ de profundidade, as seguintes características: $\mathrm{pH}\left(\mathrm{H}_{2} \mathrm{O} 1: 2,5\right)=4,81 ; \mathrm{P}=$

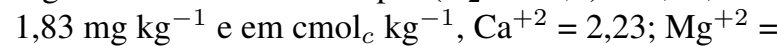
2,$51 ; \mathrm{K}^{+}=0,07 ; \mathrm{Al}^{+3}=0,48 ; \mathrm{H}^{+}=3,18 ; \mathrm{H}+\mathrm{Al}^{+3}=$ 3,$66 ; \mathrm{S}=4,81 ; \mathrm{T}=8,47 ; \mathrm{V}=56,79 \%$.

O calcário dolomítico foi aplicado de acordo com a análise de solo, tendo em vista atingir uma saturação por bases de $80 \%$ (FARIA; SILVA; MENDES, 2007). Os fertilizantes minerais foram aplicados de acordo com a análise de solos e com as recomendações de adubação de Ribeiro (1999) e Filgueira (2008), sendo distribuídos de forma localizada nos sulcos de plantio em dois tratamentos, N-5 e N-9, 50\% e 90\%, respectivamente das quantidades das referidas recomendações, tanto na adubação básica, quanto em cobertura. No tratamento N-5 foram aplicados, na adubação básica, 30, 150 e $40 \mathrm{~kg} \mathrm{ha}^{-1}$ de $\mathrm{N}, \mathrm{P}_{2} \mathrm{O}_{5}$ e $\mathrm{K}_{2} \mathrm{O}$, enquanto, no tratamento N-9, as doses foram de 52, 270 e $72 \mathrm{~kg} \mathrm{ha}^{-1}$ de $\mathrm{N}, \mathrm{P}_{2} \mathrm{O}_{5}$ e $\mathrm{K}_{2} \mathrm{O}$, respectivamente. As coberturas foram realizadas, aos 40 dias após o transplantio, nas dosagens de 30 e $35 \mathrm{~kg} \mathrm{ha}^{-1}$ de $\mathrm{N}$ e $\mathrm{K}_{2} \mathrm{O}$, para o nível de fertilizante mineral N-5 e de 54 e $63 \mathrm{~kg} \mathrm{ha}^{-1}$ de $\mathrm{Ne}$ $\mathrm{K}_{2} \mathrm{O}$, para o nível N-9.

As irrigações foram feitas por aspersão, com regas diárias, durante a fase inicial de pagamento das mudas e tempo de funcionamento em períodos de $1 \mathrm{a} 2$ horas. Após esta fase, o solo foi mantido com teor de umi- dade de $80 \%$ de água disponível e a frequência de regas variou de 1 a 3 dias, de acordo com as condições climáticas.

O controle de ervas daninhas foi realizado manualmente, sendo efetuadas quatro mondas durante todo o ciclo de desenvolvimento da cultura. O controle de doenças da parte aérea (Alternaria porri e Peronospora destructor) foi realizado com três aplicações com Dithane $\mathrm{NT}^{\circledR}$ (mancozeb), em pulverizações semanais, na dosagem de $3,0 \mathrm{~kg} \mathrm{ha}^{-1} \mathrm{e}$ mais três aplicações de Amistar WG ${ }^{\circledR}$ (azoxistrobina), na dosagem de $16 \mathrm{~g} 100$ $\mathrm{L}^{-1}$ de água do produto comercial. O controle de tripes (Trips tabacci) foi realizado com quatro aplicações de deltametrine (Decis $25 \mathrm{CE}^{\circledR}$ ), na dose de $0,3 \mathrm{ml} \mathrm{L}^{-1}$ do produto comercial.

A colheita foi realizada após o desenvolvimento vegetativo dos bulbos, quando as plantas apresentavam mais de 36\% de "estalo", ou seja, tombamento da parte aérea. Em cada parcela, foram verificados: estande final, altura da parte aérea, número de plantas que "estalaram", plantas que não bulbificaram, bem como aquelas que apresentaram podridões de bulbos e doenças da parte aérea. Os bulbos foram arrancados manualmente, permanecendo por duas semanas, para "cura", em casa de vegetação coberta com polietileno aditivado de baixa densidade, sendo, posteriormente, conservados à sombra, em local seco e ventilado.

Após o processo de "cura", os bulbos foram pesados e separados dos que apresentaram diâmetro transversal menor que $35 \mathrm{~mm}$, bem como dos que apresentaram podridões (LUENGO et al., 1999). A produção total de bulbos foi determinada pelo somatório de todos os bulbos produzidos por parcela, incluindo os que apresentaram diâmetro transversal equatorial menor que 35 $\mathrm{mm}$ e podridões de bulbos, enquanto a produção comercial foi determinada pelo somatório das classes com diâmetro maior que $35 \mathrm{~mm}$, excetuando-se, também, os que apresentaram podridões. Foram avaliadas ainda as plantas que apresentaram doenças da parte área sendo feita a contagem em cada parcela daquelas que apresentaram manchas de folhas atribuídas, principalmente aos fungos Alternaria porri (Mancha-purpúrea) e Peronospora destructor (Míldio), sem distinção do tipo de cada doença.

Os dados foram submetidos à análise de variância e regressão, sendo as médias dos diferentes tratamentos comparadas pelo teste de Tukey, a 5\% de probabilidade, utilizando-se o programa estatístico SISVAR (FERREIRA, 2000). 


\section{RESULTADOS E DISCUSSÃO}

Houve efeito significativo de forma interativa $(\mathrm{p}<0,01)$ entre as doses de composto orgânico e os níveis de fertilizantes minerais NPK na produção total de bulbos (Figura 1]. Os efeitos dos tratamentos na produção de bulbos apresentaram tendência quadrática, com valores máximos estimados de $5,78 \mathrm{~kg} \mathrm{~m}^{-2}$, na dose de 5,87 $\mathrm{L} \mathrm{m}^{-2}$ de composto, quando utilizados $50 \%$ da recomendação de adubação NPK (N-5) e de $5,10 \mathrm{~kg} \mathrm{~m}^{-2}$ na dose de $6,76 \mathrm{~L} \mathrm{~m}^{-2}$, quando aplicados $90 \%$ da recomendação de adubação (N-9). Os dados indicaram que doses crescentes de composto aumentaram a produção de bulbos de cebola, tanto no tratamento N-5 quanto em N-9, porém, evidenciando que o efeito estimado na produção foi maior com a aplicação de menores doses de fertilizantes minerais. O composto orgânico com o nível N-5 de fertilizante mineral proporcionou um aumento na produção total de bulbos de $0,68 \mathrm{~kg} \mathrm{~m}^{-2}$, correspondendo a um incremento de $11,76 \%$.

Em cultivo orgânico com cebola, cv. CNPH 6400, em Argissolo Vermelho-Amarelo câmbico e utilizando composto à base de dejetos suínos, Vidigal et al. (2010 obtiveram produtividade estimada de $60,3 \mathrm{t} \mathrm{ha}^{-1}$, com a aplicação de 43,4 $\mathrm{t} \mathrm{ha}^{-1}$ de composto, demonstrando ser possível alcançar altas produtividades de cebola sem a utilização de adubo mineral. Observou-se que os valores máximos de produção de bulbos obtidos com a cultivar Aurora, com média estimada de 57,80 $\mathrm{t} \mathrm{ha}^{-1}$ no tratamento $\mathrm{N}-5$, ficaram muito próximos da produtividade citada no trabalho anterior, demonstrando que o composto orgânico substitui parcialmente os fertilizantes minerais e aumentam a produção total de bulbos.

A produtividade varia em função do tipo de solo, das condições climáticas e da nutrição, mas está associada, principalmente, a fatores de controle genético. Resende et al. (2005) encontraram, em 11 genótipos cultivados em Vertissolo no Vale do São Francisco, produtividade total de bulbos de 19,10 a 45,11 $\mathrm{tha}^{-1}$, tendo sido o genótipo Legend o menos produtivo $\left(19,10 \mathrm{tha}^{-1}\right)$. É importante salientar que a produção total de bulbos, nesse experimento, foi superior à média nacional, de 27,82 t $\mathrm{ha}^{-1}$ (IBGE, 2014).

Houve efeito significativo dos tratamentos ( $\mathrm{p}<$ $0,01)$ entre as doses de composto orgânico e os níveis de fertilizantes minerais NPK na produção comercial de bulbos (Figura 1). A produtividade máxima estimada de bulbos comercializáveis foi de $4,77 \mathrm{kgm}^{-2}$, no tratamento N-5, para a dose de 5,83 $\mathrm{Lm}^{-2}$ de composto orgânico, enquanto, com o nível $\mathrm{N}-9$, a produtividade máxima foi de $4,55 \mathrm{kgm}^{-2}$, para a dose de $6,57 \mathrm{Lm}^{-2}$ de composto, ou seja, uma redução de $4,61 \%$ em rela- ção a N-5.

Os dados indicam que o composto orgânico apresentou melhor resposta de produtividade de bulbos comerciais, com menores níveis de NPK, inclusive exigindo a aplicação de menores doses de composto no tratamento N-5 do que no N-9, para atingir a máxima produtividade. Os incrementos médios de bulbos comerciais nos diferentes tratamentos foram de $1,92 \mathrm{~kg} \mathrm{~m}^{-2}$ com N-5 e de $0,93 \mathrm{~kg} \mathrm{~m}^{-2}$ com N-9, correspondendo a um aumento médio de $40,20 \%$ e $20,44 \%$, respectivamente, entre as doses zero e a máxima estimada. Pesquisando cebolas em diferentes sistemas de cultivo, $\mathrm{Re}-$ sende et al. (2005) observaram melhor desempenho em produtividade no tratamento orgânico, média de $24,98 \mathrm{t}$ $\mathrm{ha}^{-1}$, sendo esses valores médios superiores nas cultivares Baia Periforme, Crioula do Mercosul e no híbrido Baia F1, apresentando taxa de incremento de 27,74\%, superior à do sistema convencional.

Esse fato pode ser atribuído ao efeito quelante dos ácidos húmicos presentes na matéria orgânica, que produzem uma nutrição mais equilibrada, aumentando a capacidade de absorção de nutrientes. Tem sido comprovado, por meio de pesquisas, que os ácidos húmicos presentes na matéria orgânica estimulam o crescimento de raízes e da parte aérea das plantas, resultando em um aumento no teor de massa seca, produtividade e absorção de N, P, Fe e Cu (ABDEL-MAWGOUD et al. 2007, YILDIRIM, 2007).

A produção comercial de bulbos estimada obtida com a cv. Crioula variou de 45,5 a 47,7 $\mathrm{t} \mathrm{ha}^{-1}$, nos diferentes tratamentos. Esses dados evidenciam boas condições de adaptabilidade desse genótipo às condições da microrregião de Ariquemes, mesmo caracterizada por predominância de solos de baixa fertilidade, desde que as suas exigências nutricionais sejam devidamente supridas.

Em regiões tradicionais de produção de cebola no Vale do São Francisco, Costa et al. (2008) conduziram experimentos com o objetivo de avaliar a adaptação de genótipos de cebolas em sistema cultivo orgânico e diferentes tipos de solos. As maiores produtividades de bulbos foram alcançadas em Argissolos, variando de 13,52 a 39,52 $\mathrm{t} \mathrm{ha}^{-1}$, destacando-se as cultivares São Paulo $\left(39,52 \mathrm{t} \mathrm{ha}^{-1}\right)$ e Brisa IPA-12 (39,43 $\left.\mathrm{t} \mathrm{ha}^{-1}\right)$, que não mostraram diferenças entre si, indicando a melhor adaptação a esse tipo de cultivo e, até mesmo, redução acentuada na utilização de fertilizantes minerais.

Foi observado que, com o incremento nas doses de composto orgânico, houve um aumento no número de plantas que apresentaram podridão de bulbos. No tratamento N-9, o número máximo de plantas afetadas ocor- 

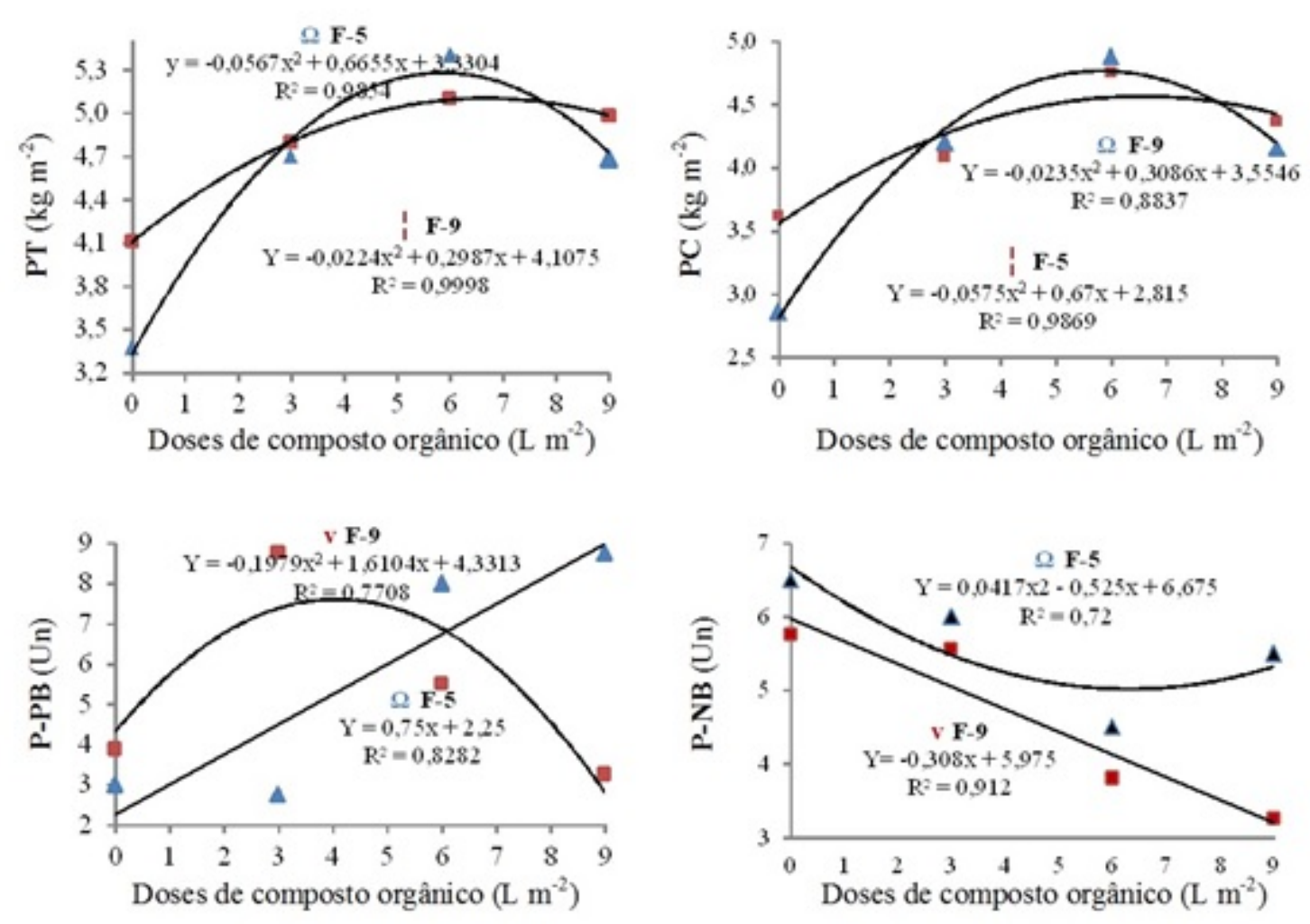

$\Omega$ F-5

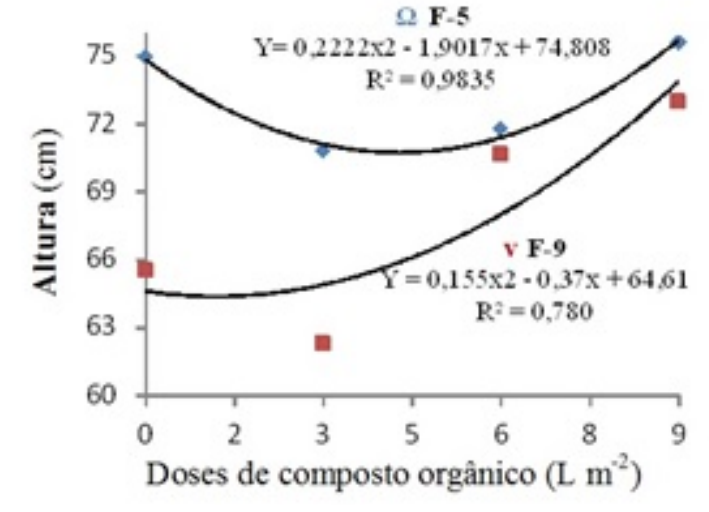

Figura 1: Produção total de bulbos (PT) de cebola, cv. Crioula, produção comercial (PC), número de plantas com bulbos podres (P-BP), plantas que não bulbificaram (P-NB) e altura de plantas, em função de diferentes doses de composto orgânico e níveis de NPK, N-5 e N-9 $50 \%$ e $90 \%$, respectivamente, da recomendação da adubação básica e em cobertura, de acordo com análise de solos em Latossolo Vermelho Amarelo. IFRO, Campus Ariquemes, RO, 2011. 
reu na dose estimada de $4,07 \mathrm{~L} \mathrm{~m}^{-2}$ de composto orgânico, total médio de 7,61 plantas por parcela, ou seja, $18,12 \%$ do estande inicial (Figura 1). No entanto, em relação ao tratamento $\mathrm{N}-5$, houve tendência de aumento linear de podridões de bulbos, alcançando, na dose máxima, perdas de 9,0 plantas por parcela, ou seja, 21,43\% do estande inicial. Os dados indicam que as perdas de produtividade devido a podridões de bulbos aumentaram com doses crescentes de composto orgânico, talvez por maior retenção de umidade no solo, próximo ao colo da planta, favorecendo o desenvolvimento de fungos e o estabelecimento de pragas, cuja colheita coincidiu com o início do período chuvoso.

Houve efeito significativo entre os tratamentos, doses de compostos orgânicos e níveis de fertilizantes minerais NPK com relação ao número de plantas que não bulbificaram em cada parcela (Figura 1). Foi observada uma tendência de redução do número de plantas que não bulbificaram com o aumento das doses de composto orgânico, em ambos os tratamentos, N-5 e N-9. Níveis mais elevados de fertilizantes minerais (N-9), utilizados com doses maiores doses de composto orgânico, aumentaram a bulbificação, sendo o efeito maior que em N-5. A redução no número de plantas que não bulbificaram com o aumento das doses de composto orgânico foi de $43,50 \%$ em N-9 e de $15,40 \%$ em N-5, entre a menor e a maior dose de composto. Esse aumento na bulbificação da cebola com o uso de composto orgânico, mesmo com menores níveis de NPK, pode ser atribuído, segundo Rodrigues e Casali (1998) a melhoria das condições físicas do solo e consequentemente da bulbificação.

Pesquisando o desempenho de dezesseis cultivares de cebola nos sistemas orgânico e convencional, em Minas Gerais, Belfort et al. (2006) observaram maior número de plantas com bulbificação em sistema orgânico do que mineral, média de 17,23 e 19,22 plantas por parcela, destacando-se cultivares Granex, Ipa-6, Serrana, Bella Crioula, Baia Periforme, Mercedes, Bola Precoce, Jubileu e Crioula do Alto Vale. Ainda segundo os mesmos autores, a bulbificação é determinada por fatores como cultivar, fotoperíodo, idade fisiológica da planta, irrigação e concentração de nitrogênio. Este último é o único fator que varia entre os sistemas de cultivo. Portanto, a menor bulbificação no sistema convencional deve-se ao manejo do nitrogênio, que aumenta a produção de bulbos com "pescoço grosso"ou "charuto" (BREWSTER; BUTLER, 2001).

Houve efeito significativo dos tratamentos, das doses de compostos orgânicos e dos níveis de fertilizantes minerais NPK em relação à altura de plantas (Figura 1).
O maior crescimento da parte aérea foi observado com a utilização de menores níveis de fertilizantes minerais em N-5 do que em N-9. No entanto, as plantas apresentaram tendência de crescimento de forma quadrática, nos tratamentos, com um aumento crescente das doses de composto orgânico, a partir de doses superiores a $1,19 \mathrm{~L} \mathrm{~m}^{-2}$, em N-9 e de 4,20 L m ${ }^{-2}$, em N-5. Doses menores de fertilizantes minerais em N-5 promoveram maior crescimento da parte aérea, mesmo em baixas doses de composto orgânico, quando comparado com níveis mais elevados de fertilizantes em N-9.

A produção de bulbos refugos foi constituída por bulbos charutos com diâmetro transversal menor que 35 $\mathrm{mm}$ e por aqueles que apresentaram podridões (Tabela 1). A produção de bulbos charutos não foi influenciada pelos diferentes tratamentos, com média de $0,59 \mathrm{~kg}$ $\mathrm{m}^{-2}$. Os valores médios estimados de bulbos charutos de 5,9 $\mathrm{tha}^{-1}$, neste trabalho, estão dentro da média referida por Costa et al.(2008), para os genótipos IPA 11, Pira Ouro e Alfa Tropical, em sistema orgânico, variando de 2,8 a $6,9 \mathrm{t} \mathrm{ha}^{-1}$, tendo sido observada significativa redução da produção comercial, tendo em vista o aumento da produtividade.

Não houve efeito significativo dos tratamentos no estande final, com média de 36 plantas por parcela, correspondendo a $85,71 \%$ do total inicial de plantas que foram transplantadas. A redução do estande final pode ser atribuída provavelmente à podridão de raízes, causada por fungos e bactérias, Fusarium sp, Colletotrichum sp. e Erwinia sp. e por doenças da parte aérea, e, ainda, ao ataque severo de Trips tabacci, cuja proliferação foi favorecida por baixa umidade relativa do ar e altas temperaturas durante o período inicial de bulbificação.

Não houve efeito significativo dos tratamentos doses de composto orgânico por níveis de fertilizantes minerais em relação ao número de plantas que apresentaram doenças da parte aérea, especialmente com relação a N-5, cuja média foi 9,0 plantas por parcela, ou seja, $21,43 \%$ do estande inicial (Tabela 1 ).

No entanto, observa-se, nesse caso, que doses maiores de fertilizantes minerais favoreceram um ligeiro aumento de doenças da parte aérea. Essas doenças podem ser atribuídas a fungos, especialmente Alternaria porri e Peronospora destructor, muito comuns durante todo o período de desenvolvimento da cebola em campo. Níveis mais elevados de nitrogênio, utilizados tanto na adubação básica quanto em cobertura, proporcionam a produção de tecidos mais tenros, podendo prolongar a fase vegetativa ou, então, retardar a maturidade da planta, criando condições favoráveis ao ataque de pa- 
Tabela 1: Produção de bulbos "charutos", estande final e número de plantas de cebola que apresentaram doenças da parte aérea, cv. Crioula, em função de diferentes doses de composto orgânico e níveis de NPK em Latossolo Vermelho Amarelo. IFRO, Campus Ariquemes, RO, 2011.

\begin{tabular}{ccccc}
\hline $\begin{array}{c}\text { Composto orgânico } \\
\left(\mathrm{L} \mathrm{m}^{-2}\right)\end{array}$ & $\begin{array}{c}\text { Bulbos "charutos" } \\
\left(\mathrm{kg} \mathrm{m}^{-2}\right)\end{array}$ & $\begin{array}{c}\text { Estande final } \\
(\text { no. de plantas) }\end{array}$ & $\begin{array}{c}\text { Doenças da parte aérea } \\
\text { (no. de plantas) } \\
\text { N-5 }\end{array}$ & \begin{tabular}{c} 
N-9 \\
\hline 0
\end{tabular} \\
$0,51 \mathrm{a}$ & $35 \mathrm{a}$ & $8,8 \mathrm{a}$ & $7,0 \mathrm{a}$ \\
3 & $0,61 \mathrm{a}$ & $36 \mathrm{a}$ & $10,8 \mathrm{a}$ & $8,3 \mathrm{a}$ \\
6 & $0,44 \mathrm{a}$ & $37 \mathrm{a}$ & $8,0 \mathrm{a}$ & $10,5 \mathrm{a}$ \\
9 & $0,79 \mathrm{a}$ & $37 \mathrm{a}$ & $8,5 \mathrm{a}$ & $7,5 \mathrm{a}$ \\
Média & 0,59 & 36 & 9,0 & 7,5 \\
\hline $\mathrm{CV}(\%)$ & 11,69 & 7,86 & 18,72 & 18,72 \\
\hline
\end{tabular}

Na coluna, médias seguidas pela mesma letra não diferem entre si, pelo teste de Tukey, a 5\% de probabilidade. N-5 e N-9 indicam, respectivamente, $50 \%$ e $90 \%$ da recomendação da adubação básica e em cobertura para a cebola, de acordo com análise de solos local.

tógenos (ALVARENGA, 2004).

O ciclo cultural da cebola 'Crioula', nas condições de inverno nas regiões sul e sudeste do Brasil, é de 185 dias. No entanto, nas condições deste experimento, foi de apenas 131 dias, apresentando uma redução de 54 dias, devido às condições climáticas da região, de altas temperaturas e luminosidade durante o período de crescimento e desenvolvimento da cultura. É importante ressaltar que houve maior produção de bulbos das classes III e IV, indicando que a bulbificação não foi muito afetada pelos fatores climáticos, embora o ciclo da cultura tenha sido reduzido consideravelmente.

\section{CONCLUSÕES}

A produtividade máxima estimada de bulbos comercializáveis, ocorreu em doses médias de composto orgânico e com aplicação de apenas $50 \%$ da recomendação de adubação NPK.

$\mathrm{O}$ número de plantas que bulbificaram aumentou com doses crescentes de composto orgânico, sendo observado um efeito linear crescente no tratamento com apenas $50 \%$ de da recomendação de adubação NPK.

Doses crescentes de composto orgânico não aumentaram de forma significativa as doenças da parte aérea da planta, independente dos níveis de NPK utilizados.

\section{REFERÊNCIAS}

ABDEL-MAWGOUD, A.; EL-GREADLY, N.; HELMY, Y.; SINGER, S. Responses of tomato plants to different rates of humic-based fertilizer and npk fertilization. Journal of Applied Sciences Research, v. 3, n. 2, p. 169-174, 2007.

\begin{abstract}
ALVARENGA, M. A. A. R. Nutrição mineral e adubação. In: ALVARENGA MAR (Ed.). Tomate: produção em campo, em casa-de-vegetação e em hidroponia. : UFLA, 2004.
\end{abstract}

ANGELETTI, M. d. P.; FONSECA, A. da. Instrucoes tecnicas para o cultivo comercial de cebola em rondonia. EMBRAPA-UEPAE Porto Velho. Circular Tecnica, Porto Velho: EMBRAPA-UEPAE Porto Velho., v. 1, n. 12, p. 21, 1987.

BELFORT, G.; NAKADA, P. G.; SILVA, D.; DANTAS, G. G.; SANTOS, R. R. Desempenho de cultivares de cebola nos sistemas orgânico e convencional em minas gerais. Horticultura Brasileira, Associação Brasileira de Olericultura, v. 24, p. 206-209, 2006.

BREWSTER, J.; BUTLER, H. Effects of nitrogen supply on bulb development in onion allium cepa 1. Journal of Experimental Botany, Oxford University Press, v. 40, n. 10, p. 1155-1162, 2001.

COSTA, N. D.; ARAÚJO, J. F.; SANTOS, C. A. F.; RESENDE, G.; LIMA, M. Desempenho de cultivares de cebola em cultivo orgânico e tipos de solo no vale do são francisco. Horticultura Brasileira, SciELO Brasil, v. 26, n. 4, p. 476-480, 2008.

DIAS, V. P.; FERNANDES, E. Fertilizantes: uma visão global sintética. BNDES Setorial, v. 1, n. 24, p. 97-138, 2006.

FARIA, C. M. B.; SILVA, D. J.; MENDES, A. M. S. Cultivo da cebola no nordeste: nutrição. Petrolina, PE: Embrapa Semiárido, 2007. 
EFEITO DE DIFERENTES DOSES DE COMPOSTOS ORGÂNICOS E FERTILIZANTES NPK NO DESENVOLVIMENTO E PRODUTIVIDADE DE CEBOLA

FERREIRA, D. F. Sistemas de análise estatística para dados balanceados. Lavras: DEX/Sisvar, 2000.

FILGUEIRA, F. A. R. Novo manual de Olericultura: agrotecnologia moderna na produção e comercialização de hortaliças. Lavras: Editora UFLA, 2008.

IBGE. Produção Agrícola Municipal (ano 1990 a 2014). Banco de Dados Agregados. Sistema IBGE de Recuperação Automática - SIDRA. 2014. Disponível em: <http://www.sidra.ibge.gov.br/bda/agric/> Acesso em: 30 abr. 2016.

LIMA, A. A. d.; SILVA, H. dos S.; SANTOS, C. H. dos; MENDONÇA, J. L. de; FILHO, L. C. de M.; OLIVEIRA, J. R. de. Desempenho e produtividade de genótipos de cebola em argissolo na região sul de rondônia. Current Agricultural Science and Technology, v. 17, n. 2, p. 185-192, 2011.

LUENGO, R. d. F. A.; CALBO, A. G.; LANA, M. M.; MORETTI, C. L.; HENZ, G. P. Classificação de hortaliças. Embrapa Hortaliças-Documentos (INFOTECA-E), Brasilia: Embrapa Hortalicas, 1999. v. 1, n. 22, p. 61, 1999.

MENEZES, S. F. M.; LOCATELLI, M. Sistemas agroflorestais e fertilidade dos solos: uma análise da microrregião de Ariquemes, Rondônia. Dissertação (Mestrado) - Universidade Federal de Rondônia, Porto Velho, 2008.

OLIVEIRA, A. M. G.; AQUINO, A. M. de; NETO, M. T. d. C. Compostagem caseira de lixo orgânico doméstico. Embrapa Agrobiologia-Circular Técnica (INFOTECA-E), Cruz das Almas: Embrapa Mandioca e Fruticultura Tropical, 2005, v. 1, n. 76, p. 1-6, 2005.

PAES, J. M. V.; ANDREOLA, F.; BRITO, C. H. de; LOURDES, E. G. Decomposição da palha de café em três tipos de solo e sua influência sobre a ctc e o ph. Ceres, v. 43, n. 249, p. 575-683, 1996.

RESENDE, G. M. d.; COSTA, N. D.; SANTOS, C. A.; SANTOS, G. M.; LEITE, W. M. de. Desempenho produtivo de genótipos de cebola em vertissolo no vale do são francisco. Embrapa Semiárido-Artigo em periódico indexado (ALICE), Caatinga, Mossoró, v. 18, n. 4, p. 210-214, out./dez. 2005., v. 18, n. 4, p. 210-214, 2005.

RIBEIRO, A. C. Recomendações para o uso de corretivos e fertilizantes em Minas Gerais: 5.
Aproximação. : Comissão de Fertilidade do solo do estado de Minas Gerais, 1999.

RODRIGUES, E. T.; CASALI, V. W. D. Resposta da alface à adubação orgânica. ii. teores, conteúdos e utilização de macronutrientes em cultivares. Ceres, v. 45, n. 261, p. 437-449, 1998.

SEDAM, S. d. E. d. D. A. Boletim climatológico de rondônia - 2010. In: Governo de Rondônia. Porto Velho, RO: , 2012. v. 12.

SILVA, J. E.; RESCK, D. V. S. Biologia dos solos dos cerrados. In: VARGAS, M. A.; HUNGRIA, M. (Ed.). Matéria orgânica do solo. : EMBRAPA-CPAC, 1997. p. 467-524.

VIDIGAL, S. M.; SEDIYAMA, M. A. N.; PEDROSA, M. W.; SANTOS, M. d. Produtividade de cebola em cultivo orgânico utilizando composto à base de dejetos de suínos. Horticultura Brasileira, SciELO Brasil, v. 28, n. 2, p. 168-173, 2010.

YILDIRIM, E. Foliar and soil fertilization of humic acid affect productivity and quality of tomato. Acta Agriculturae Scandinavica Section B-Soil and Plant Science, Taylor \& Francis, v. 57, n. 2, p. 182-186, 2007. 